\title{
Research on Sustainable Development Evaluation and Spatial Distribution Characteristics of Resource-based Cities in Heilongjiang Province
}

\author{
Suning Xu, School of Architecture, Harbin Institute of Technology, Key Laboratory of Cold \\ Region Urban and Rural Human Settlement Environment Science and Technology, Ministry of \\ Industry and Information Technology, Harbin 150006, China \\ Chao Dai, School of Architecture, Harbin Institute of Technology, Key Laboratory of Cold \\ Region Urban and Rural Human Settlement Environment Science and Technology, Ministry of \\ Industry and Information Technology, Harbin 150006, China \\ Xiaochen Wu, School of Architecture, Harbin Institute of Technology, Key Laboratory of Cold \\ Region Urban and Rural Human Settlement Environment Science and Technology, Ministry of \\ Industry and Information Technology, Harbin 150006, China
}

\begin{abstract}
As a representative of the old industrial base in Northeast China, the resource-based cities in Heilongjiang Province provided a large number of materials, funds and talents for the completion of industrialization. However, with the continuous consumption of resources, resource-based cities are in urgent need of transformation and development. This paper builds a sustainable development evaluation system based on the factor analysis method, takes 8 resource-based cities in Heilongjiang Province as the research object, analyzes the development characteristics of resource-based cities from 2009 to 2018, and uses autocorrelation analysis, the center of gravity migration and other methods to analyze the development characteristics of resource-based cities. Research on the spatial distribution characteristics of cities. The study found that: (1) The resource-based cities in Heilongjiang Province have 3 mature, 3 declining and 2 are in the stage of transition from mature to declining. (2) Yichun, Hegang, Qitaihe and Shuangyashan cities are highly dependent on resource reserves and it is difficult to get rid of resource exhaustion. (3) Resource-based cities in Heilongjiang Province are concentrated in the northeast, and the center of sustainable development gradually migrates to the southwest.
\end{abstract}

\section{Keywords}

resource-based cities, sustainable development, autocorrelation analysis, spatial distribution

\section{Introduction}

Resource-based cities are a type of city that emerged with the large-scale development and 
utilization of mineral resources after the advent of the industrialization era in the 18th century. Resource-based cities (including resource-based regions) are urban communities formed by mining and processing natural resources such as minerals and forests in the region and then extending based on living settlements. This type of city generally takes a short time to form and is very different from traditional commercial cities in terms of historical accumulation, industrial model, and population composition. Due to the special functions of resource-based cities in the economic field and the series of contradictions and impacts in industry, society, and the environment that it triggers, they have attracted the attention of experts and scholars around the world (Zhao, J.H., 2006). The research on resource-based cities can be traced back to the 1930s. The most significant studies are in Canada, the United States, and Australia, (Karen Williamson, 2003; Papurakis, E. and Gerlagh, R, 2007).

The research on resource-based cities can be divided into four stages, (Hardi, P., Barg, S., Hodge, T. eds., 1997). The first stage was from the 1930s to the 1970s. Scholars studied the individual behavior, social problems and population mobility of resource-based cities under the optimistic spirit of pioneers. During this period, individual empirical studies were mainly conducted on a single city or several towns in a specific area. The research content focused on the characteristics of demographic changes, architectural and town planning issues, and many social and psychological issues in remote towns with a single industry. superior. The second stage was from the 1970s to the 1980s. Scholars studied the status and influence of resource companies, the life cycle of cities, and the flow of resources and benefits from a common perspective, and explored the use of urban planning to promote industrial agglomeration and improve the quality of life of community residents. The third stage is from the 1980 s to the end of the 1990s, turning to the economic, labor structure, and the impact of world economic integration on resource-based cities, using sociology and behavioral theories to examine the reasons for the instability of resource-based communities and interacting with communities research. The fourth stage, from 2000 to the present, has studied special sustainable development areas, such as the transformation of resource-based cities, the social impact of mining from changes, and urban environmental protection. In recent years, it has focused on the discussion of urban sustainability caused by changes in the industrial structure and labor market brought about by technological progress and management innovation, and the contradiction between resource extraction and the social environment, (Zhao eds., 2019).

Resource-based cities can be divided into two categories: one type is formed by the discovery and exploitation of resources after the city; the other type is more typical, which is the discovery of resources first, and after large-scale development, it is divided into blocks, (Dai, X.F., 2009). With the increase of developers and children of their families, some supporting facilities for life will be built in the resource area of the country, and gradually formed under the support of the state. At present, most of the resource-based cities in Heilongjiang Province belong to the latter type. There are many resource-based cities in Heilongjiang Province. For a long time, as a source of basic energy and important raw materials, these resource-based cities have made outstanding contributions to China's economic and social development. However, due to the single industrial structure and the continuous decline in resource prices, resource-based cities have suffered from economic stalls, increasingly troubled local finances, increasing unemployment, deteriorating ecological environment, backward infrastructure construction, and prominent social conflicts. And structural economic and social problems, falling into the dilemma of "mine exhaustion city decline", "mine exhaustion city collapse", and its sustainable development is facing severe challenges. Therefore, this article establishes a sustainable development evaluation system for the resource reserves of resource-based cities, to classify 
the development of resource-based cities in Heilongjiang Province.

\section{Research objects and methods}

\subsection{Research objects}

Heilongjiang Province is located in Northeast China is shown in Figure 1, rich in mineral resources, and rich in oil, coal and forest resources. According to the National Sustainable Development Plan for Resource-Based Cities (2013-2020), State Council of China (2013), there are currently 9 prefecture-level cities as resource-based cities, including Heihe City, Daqing City, Yichun City, Hegang City, Shuangyashan City, and Qiataihe City. Taihe City, Jixi City, Mudanjiang City, Daxinganling area. The data used in the project comes from the China City Statistical Yearbook (2009-2018) and the Heilongjiang Province Statistical Yearbook (2009-2018). Due to the poor availability of data in the Daxinganling area, and the lack of data in individual years, in this research, in addition to the Daxinganling area, 8 other resource-based cities in Heilongjiang Province will be the research objects. According to the "Statistical Yearbook of Heilongjiang Province", at the end of 2017, the total population of the 8 resource-based cities was 12.54 million, the gross national product was 345.377 billion yuan, and the land area was 228,300 square kilometers, accounting for $35.8 \%, 36.6 \%$ and $58.3 \%$ of Heilongjiang Province respectively.

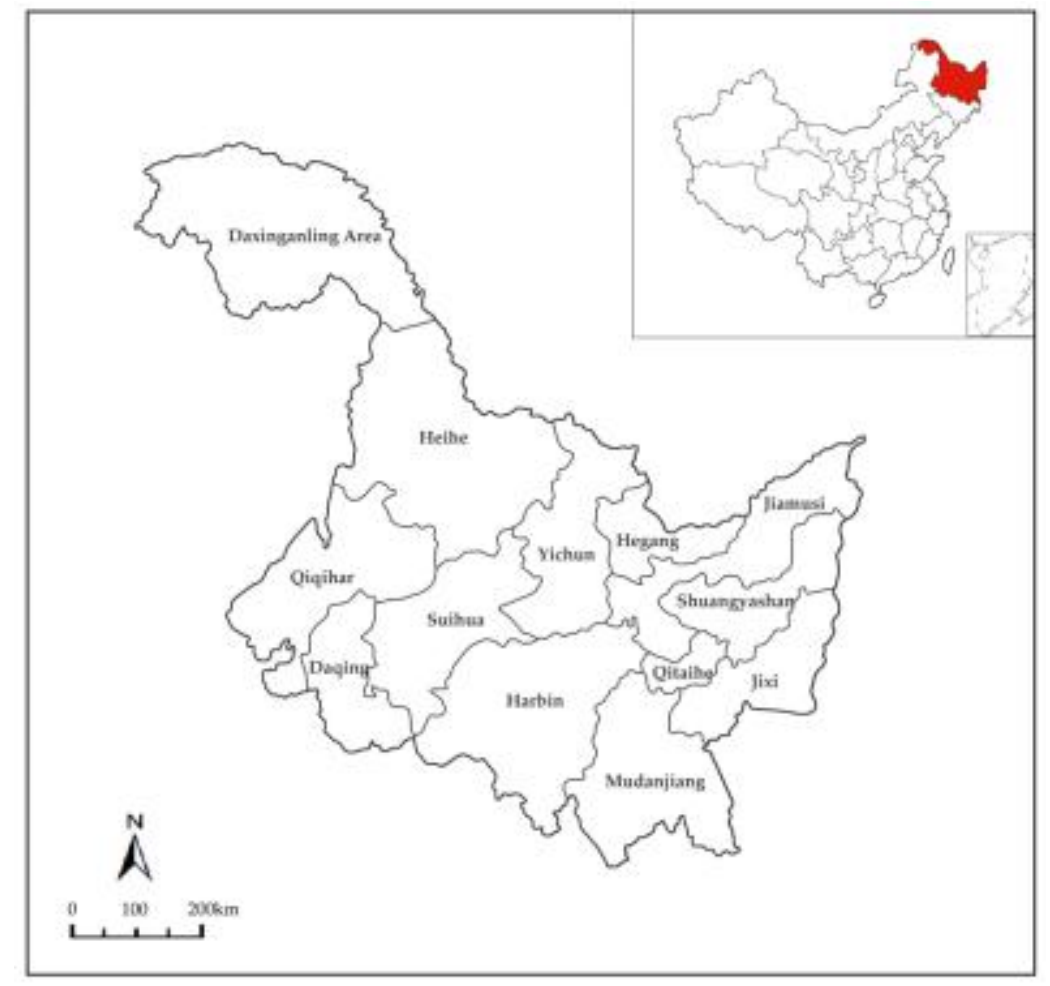

Figure 1. Location of Heilongjiang Province. Source:Painted by the author.

\subsection{Research methods}

There are two categories of indicators in the sustainable development evaluation index system of resource-based cities. One is level indicators, such as per capita GDP, and the other is speed indicators, such as GDP growth rate. According to the descriptions of various types of indicators, different judgment standards are adopted for level indicators and speed indicators. 
For the level indicator, $10 \%$ lower than the national average level, judged as growth type; between $10 \%$ and $15 \%$, judged as mature type; between $15 \%$ and $20 \%$, judged as declining type; higher than the national average level $20 \%$, judged as regenerative type. As for the speed index, it is $2 \%$ lower than the national average and judged as a growth type; between $2 \%$ and $3 \%$ is judged as a mature type; between $3 \%$ and $4 \%$ is judged as a recession type; higher than the national average $4 \%$, judged as regenerative type, (Li, F. eds., 2009).

According to the above judgment principle, the research constructs a segment function representing the membership relationship between the resource-based city score and the sustainable development stage, based on the membership function. Then choose the five-point system scoring method, the golden ratio method, and set the index score value as $1,3,5$. If the function value is negative, it means better than average; if the function value is positive, it means lower than average. Among them, 1 point indicates the sustainable development stage, 3 points indicates the sustainable development mature stage, and 5 points indicate the sustainable development decline stage. The specific functions are as follows:

$$
f(x)=\left(x_{i j k}-x_{i k}\right) / x_{i k}
$$

In the formula, $f(x)$ represents the specific index assignment, $x_{i j k}$ and $x_{i k}$ respectively represents the index value of the $j$ th index of the $i$ th city in the $k$ th year and the average value of the $i_{\text {th }}$ index in the country in the same year.

When determining the sustainable development stage of a resource-based city each year, a percentile system is usually used, with $0-40$ as the growth type, 41-55 as the mature type, 5675 as the declining type, and $76-100$ as the regenerative type. According to the number of indicators and the sum of scores, the theoretical score is converted into the actual score which is used as the criterion. The specific conversion method is as follows: weighted summation is carried out according to the number of selected indicators and the upper limit score of each indicator. The total score of the indicator system is calculated as 75 points. Based on the $100-$ point system, the standard for the transformation stage of resource-based cities is converted. Taking the growth type as an example, the theoretical score is $0-40$, the actual score can be calculated by $75 \times 40 / 100=30$. So $0-30$ is the judgment of growth type. The conversion method is the same for other stages are showing in Table 1.

Table 1 Resource-based cities are identified by annual sustainable development stages

\begin{tabular}{ccccc}
\hline $\begin{array}{c}\text { Resource-based } \\
\text { city } \\
\text { classification }\end{array}$ & Growth type & Mature & Declining & Regenerative \\
\hline $\begin{array}{c}\text { Theoretical } \\
\text { score }\end{array}$ & $0 \sim 40$ & $41 \sim 55$ & $56 \sim 75$ & $76 \sim 100$ \\
Actual score & $0 \sim 30$ & $31 \sim 41$ & $42 \sim 56$ & $57 \sim 75$ \\
\hline
\end{tabular}




\section{Evaluation system establishment and classification}

\subsection{Sustainable Development Evaluation System of Resource-based Cities}

This article combines the "National Resource-based City Sustainable Development Plan (20132020)" and related resource-based city development indicators, Liu, Y. and Liu, Y.(2003), Zhang, K.M. (1997), from population scale, economic development level, social development level, infrastructure construction, environmental pollution control and industrial structure 6 On the one hand, Yang, D.G. and Niu, W.Y. (eds.) (2000), Zhang, W.Z. Yu, J.H. Wang, D. (eds.) (2014), establish a sustainable development evaluation system for resource-based cities are shown in Table 2.

Table 2 Sustainable Development Evaluation System of Resource-based Cities

\begin{tabular}{|c|c|c|}
\hline Overall objective & First level indicator & Secondary indicators \\
\hline \multirow{15}{*}{$\begin{array}{l}\text { Sustainable } \\
\text { development of } \\
\text { resource-based } \\
\text { cities }\end{array}$} & & Population density (person/km2) \\
\hline & Population size & $\begin{array}{l}\text { Total population at the end of the year }(10,000 \\
\text { people) }\end{array}$ \\
\hline & \multirow{4}{*}{$\begin{array}{c}\text { The level of economic } \\
\text { development }\end{array}$} & Resource output rate (\%) \\
\hline & & GDP growth rate (\%) \\
\hline & & Per capita local fiscal revenue (yuan/person) \\
\hline & & Per capita net income of rural residents (yuan/person) \\
\hline & \multirow{3}{*}{$\begin{array}{l}\text { Social development } \\
\text { level }\end{array}$} & $\begin{array}{l}\text { The proportion of expenditure on science and } \\
\text { technology education in fiscal expenditure (\%) }\end{array}$ \\
\hline & & Proportion of non-extractive industry employees (\%) \\
\hline & & Urban registered unemployment rate (\%) \\
\hline & \multirow{2}{*}{ infrastructure } & Urban road area per capita (km2/person) \\
\hline & & Green coverage rate in built-up area (\%) \\
\hline & \multirow{2}{*}{$\begin{array}{l}\text { Environmental } \\
\text { pollution control }\end{array}$} & $\begin{array}{l}\text { Comprehensive utilization rate of industrial solid } \\
\text { waste (\%) }\end{array}$ \\
\hline & & Total discharge of major pollutants ( 10,000 tons) \\
\hline & \multirow{2}{*}{ Industrial structure } & $\begin{array}{l}\text { Proportion of the output value of the primary industry } \\
\text { (\%) }\end{array}$ \\
\hline & & $\begin{array}{l}\text { The proportion of the output value of the secondary } \\
\text { industry (\%) }\end{array}$ \\
\hline
\end{tabular}

\subsection{Sustainable Development Evaluation System of Resource-based Cities}

In order to deeply analyze the development status of resource-based cities in Heilongjiang Province, and put forward more targeted sustainable development strategies, sustainable development is divided into four stages of growth, maturity, decline and regeneration, among which the growth theory score value It is $0-30$, mature type is $31-41$, degenerate type is $42-56$, and regenerative type is $57-75, \mathrm{Xu}, \mathrm{J} . \mathrm{Z}$. and Liu, X.S. (eds.) (2002). According to the adjusted 
sustainable development stage of resource-based cities, 8 resource-based cities in Heilongjiang Province were judged is shown in Table 3.

Table 3 Judgment of the sustainable development stage of resource-based cities in Heilongjiang Province

\begin{tabular}{ccccccccccccccc}
\hline City & 2008 & 2009 & 2010 & 2011 & 2012 & 2013 & 2014 & 2015 & 2016 & 2017 & $\begin{array}{c}\text { Average } \\
\text { value }\end{array}$ & The stage \\
\hline Jixi City & 22 & 28 & 32 & 35 & 37 & 37 & 39 & 37 & 44 & 45 & 35.6 & Mature \\
$\begin{array}{c}\text { Hegang } \\
\text { City }\end{array}$ & 33 & 33 & 35 & 35 & 40 & 41 & 42 & 49 & 51 & 57 & 41.6 & $\begin{array}{c}\text { Mature to } \\
\text { Declining }\end{array}$ \\
$\begin{array}{c}\text { Daqing } \\
\text { City }\end{array}$ & 31 & 33 & 37 & 41 & 43 & 41 & 41 & 41 & 43 & 44 & 39.5 & Mature \\
$\begin{array}{c}\text { Mudanjian } \\
\text { g City }\end{array}$ & 35 & 41 & 39 & 41 & 40 & 42 & 44 & 44 & 43 & 45 & 41.4 & $\begin{array}{c}\text { Mature to } \\
\text { Declining }\end{array}$ \\
$\begin{array}{c}\text { Heihe City } \\
\begin{array}{c}\text { Shuangyas } \\
\text { han City }\end{array}\end{array}$ & 35 & 35 & 41 & 40 & 41 & 41 & 39 & 43 & 41 & 41 & 39.7 & Mature \\
$\begin{array}{c}\text { Qitaine } \\
\text { City }\end{array}$ & 35 & 43 & 47 & 47 & 47 & 45 & 41 & 43 & 49 & 51 & 44.8 & Declining \\
$\begin{array}{c}\text { Yichun } \\
\text { City }\end{array}$ & 41 & 43 & 47 & 54 & 56 & 56 & 55 & 55 & 56 & 53 & 51.6 & Declining \\
\hline
\end{tabular}

According to the status quo of sustainable development of resource-based cities in Heilongjiang Province, the 8 resource-based cities can be divided into three categories, Yu, J.H, Li, J.M, Zhang, W.Z. (2018). The first category is mature resource-based cities, including Jixi City, Heihe City, and Daqing City; the second category is Hegang City and Mudanjiang City, which are in the transition stage from mature to recession; and the third category is recession. Including Shuangyashan City, Qitaihe City and Yichun City. From the perspective of time, the sustainable development of resource-based cities in Heilongjiang Province has generally been in a state of decline. Specifically, it can be roughly divided into three stages: the first stage is from 2008 to 2009, the scores of various indicators are low, and the rate of resource decline is slow; the second stage is from 2010 to 2011, and the changes of various indicators are relatively slow. The third stage is 2012-2017. Due to the national energy-saving and emission-reduction policies and supply-side reforms, the development of green and clean energy, the reduction of outdated production capacity, the reduction of coal and other energy output, and the decline in prices. It has a direct impact on the economy and resources industry of Heilongjiang Province, and then affects the environment and people's livelihood indicators, which slows down the development of various indicators at this stage.

\subsubsection{Analysis on the Development Characteristics of Mature Cities}

The sustainable development of Jixi City has gone through three stages. Although it is currently a mature resource-based city, it was a growth-oriented resource-based city before 2010, with sufficient urban resource reserves and steady social and economic development. From 2010 to 
2015 , it has been in a relatively mature stage of resource development and utilization, but there have been signs of decline in 2016; Daqing City has shown a trend of continuous development from a mature type to a declining type from 2008 to 2011, but in 2012 After entering the recession period, urban development has been constantly fluctuating between mature and declining types. In addition, in 2014, international oil prices fell and oil production decreased, although the sustainable development of Daqing City is still at the end of its maturity. However, in 2015, Daqing's economy experienced a cliff-like decline, with negative growth for the first time; the sustainable development of Heihe City was much more stable, and it has remained at the end of its maturity since 2010. It can be seen from the analysis of city-related data that the level of social development is the key to restricting the sustainable development of mature cities. The proportion of expenditures on science, technology and education has fallen year after year, the number of urban unemployed people has continued to increase, and the proportion of nonextractive industry employees has continued to rise. Resource-based cities have been moving closer from mature to declining development.

\subsubsection{Analysis on the Development Characteristics of Mature to Declining Cities}

Mudanjiang City and Hegang City entered the declining development stage from the mature type in 2013 and 2014. After Mudanjiang entered the recession period, it still maintained a relatively slow recession process, while Hegang City's sustainable development level declined sharply from 2015 to 2017 , and reached the peak of the recession in 2017. By comparing relevant city data, it is found that the rapid decline node of economic development basically coincides with the node of urban development transformation. The GDP growth rate of Mudanjiang City dropped by nearly 8 percentage points in 2012 compared to 2011, while the GDP growth rate of Hegang City experienced negative growth for the first time in 2014 . With the decline in per capita GDP, these cities have accelerated their decline and joined The ranks of declining cities.

\subsubsection{Analysis on the Development Characteristics of Declining Cities}

It can be seen from Table 3 that Shuangyashan City, as the most severely declining city, its sustainable development resources have been in a declining stage since 2008. After 2010, it showed a slow growth trend and reached the maximum in 2014. Qitaihe City and Yichun City were both in a mature development stage in 2008, and have entered a period of sustainable development decline since 2009. Compared with Yichun City, Qitaihe City's resource decline was slower, until 2016 began to accelerate the decline, and reached a peak in 2017. Yichun City's resource reserves declined significantly from 2008 to 2011, and remained at a relatively stable level after 2011. At present, the sustainable development level of resources in Shuangyashan City is the lowest. By comparing various indicators, it is found that although the total population of the three cities has decreased, the population loss in Shuangyashan City is the most serious. The population has decreased by nearly 600,000 in 10 years, which is three times the population loss of the other two cities. . Large-scale population loss is the most important factor influencing the low level of sustainable development in Shuangyashan City. 


\section{The spatial distribution characteristics of resource-based cities in Heilongjiang Province}

\subsection{Spatial distribution characteristics}

This paper selects four time intervals of three years in 2008, 2011, 2014, and 2017 to analyze the sustainable development of resource-based cities in Heilongjiang Province. It can be seen from the figure 2 that the resource-based cities in Heilongjiang Province are mainly distributed in the north and east. As the only resource-based city located in the south, the sustainable state of Daqing City is relatively stable. It has been maintained in a mature period and gradually transitioned to a decline period. From 2008 to 2011, the status of only two cities changed: Qitaihe City changed from a mature period to a decline period, and Jixi City changed from a growth period to a mature period, Zang, S.Y. (1999). At this stage, the overall state of the northern cities is relatively stable, but the development process of the eastern cities is relatively fast. From 2011 to 2014, a city in the north entered a period of decline from a mature period, and the three resource-based cities in the east changed. Shuangyashan City changed from a declining type to a regenerative type, and was the first resource city in Heilongjiang Province to transform into a regenerative type. Mudanjiang City has entered a recession type from maturity, and Qitaihe City has turned from a recession type to a mature type. At this stage, the development of northern cities is relatively stable, and the development differences of eastern cities are more obvious. In 2014-2017, only one city in the northern city changed its status, that is, Hegang City changed from a declining type to a regenerative type. The remaining two cities in the eastern cities have also turned into a recession type. Since then, all eastern cities have entered a state of decline and above. At this stage, the development level of eastern cities is slightly better than that of northern cities.
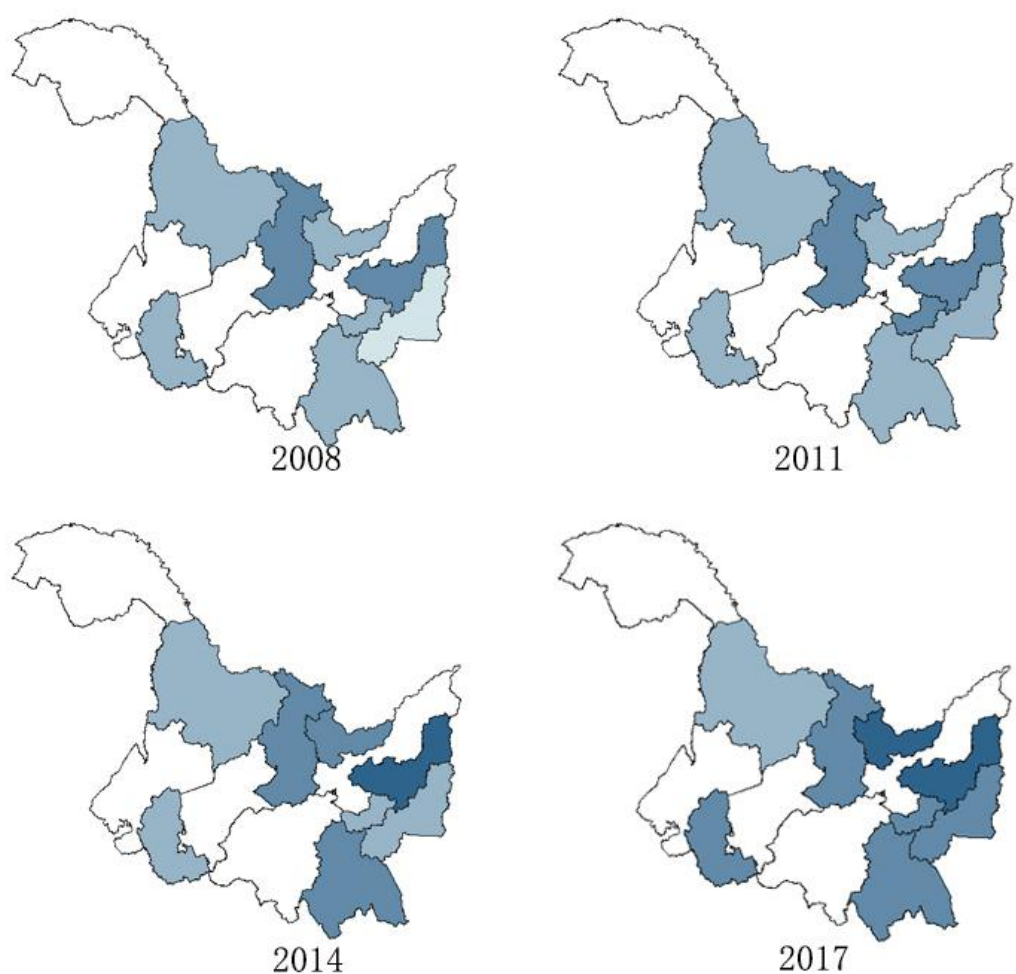

2011

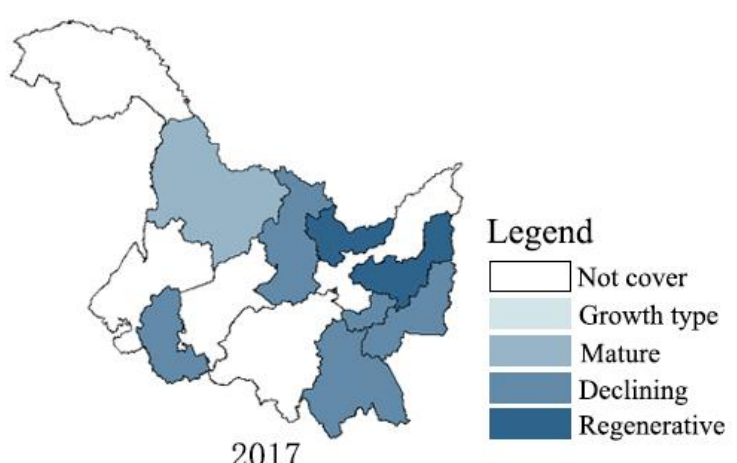

Figure. 2 Spatial pattern of Sustainable Development of Resource-based Cities in Heilongjiang Province 


\subsection{Center of gravity offset feature}

Using ArcGISd to analyze the average center of gravity and standard ellipse deviation of the shift of the center of gravity of the resource-based cities in Heilongjiang Province, the results are shown in Figure 3 and Figure 4, Thorson, J.T, Pinsky, M.L, Ward, E.J (2016). It can be seen that the focus of sustainable development of resource-based cities in Heilongjiang Province lies in Jiamusi City, which is close to Yichun City and Harbin City. The trajectory of the center of gravity changes from southeast to northwest to northeast to southeast, and gradually moves to the east as a whole, which is consistent with the analysis results in 4.1. The sustainable development level of resource-based cities in the east is generally good, so the center of gravity is shifted to the east. In the process of resource-based city transformation, affected by national and local policies, the city did not fully follow the process of sustainable development. For example, Qitaihe City experienced a decline in the state of sustainable development during the 2011-2014 period. Therefore, the center of gravity will shift in different directions and intensities during the process of migration, Austin, D.A (2006).

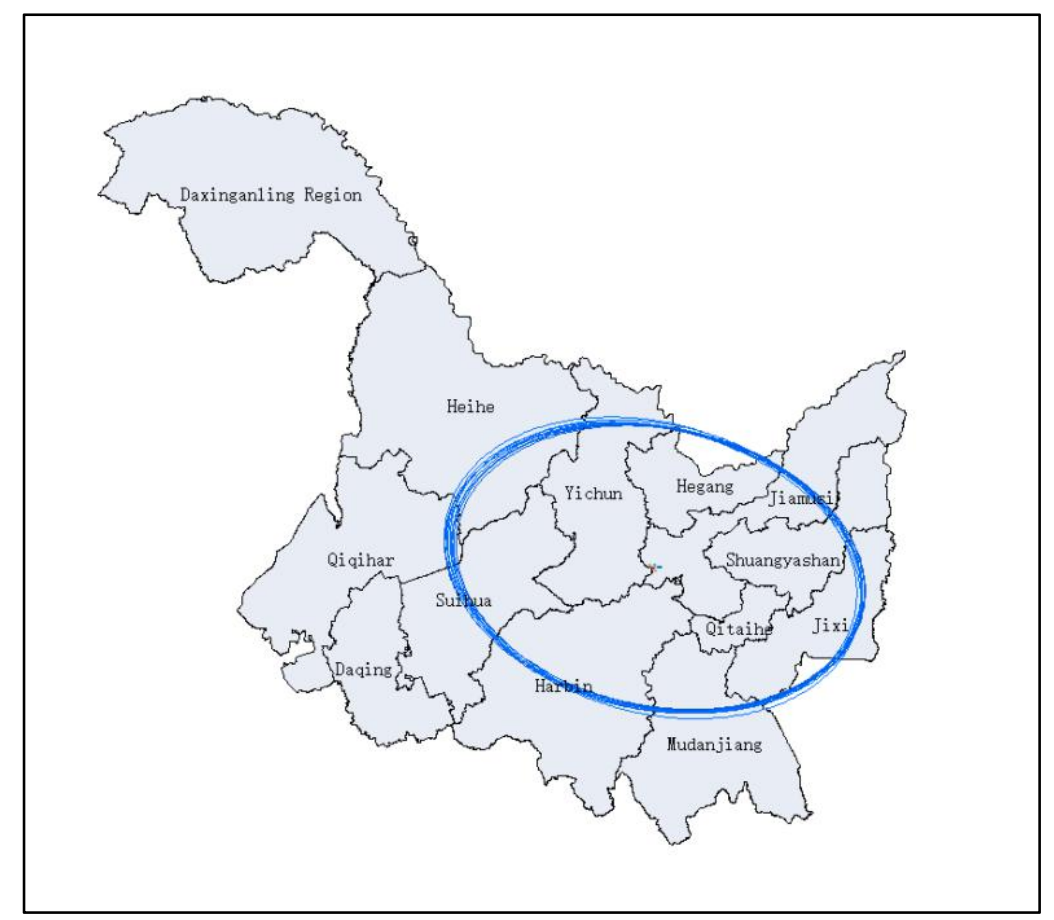

Figure. 3 Spatial pattern of Sustainable Development of Resource-based Cities in Heilongjiang Province 


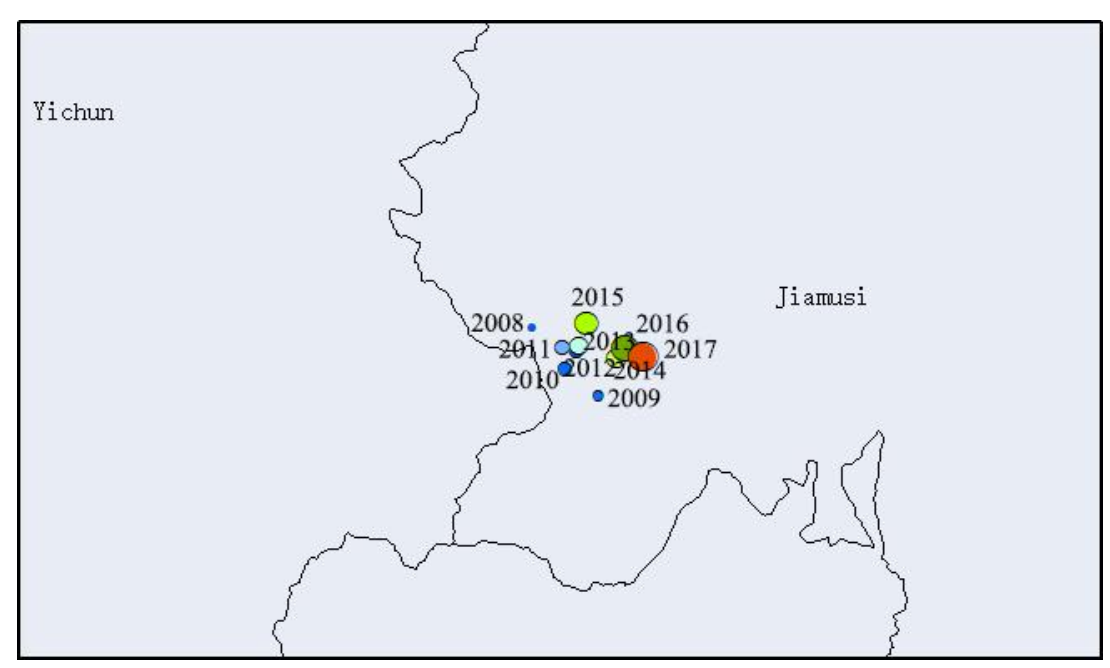

Figure. 4 Spatial pattern of Sustainable Development of Resource-based Cities in Heilongjiang Province

\section{Conclusion}

(1) Most resource-based cities are built as a result of the development of resources, and resources are the lifeblood of such cities. For a long time, resources have indeed laid the material foundation for its development. However, the GDP of resource-based cities mainly relies on resources, the industry is too single, and the economic development presents a trend of "relying on the sky to feed", and finally formed the mine-based city and the mine-exhausted city, Zhang, J.T. (2003). The vicious circle of decline. Since the protection of natural forests, the development of timber in Daxinganling and Daxinganling has stopped, Hu, Z.C.(2018). Due to the lack of alternative industries, the economic recession in Yichun and Daxinganling has been severe and the potential for development is seriously insufficient. (2) Severe population loss and insufficient urban development competitiveness. Resource-based cities are mostly immigrant cities, and the large population is due to the migration of resource extraction. With the reduction in resource production, all resource-based cities have experienced a decline in economic benefits and a shortage of jobs, which will inevitably lead to a large outflow of people to find new employment outlets. In recent years, under the general economic downturn in Northeast China, the population of resource-based cities in Heilongjiang Province has been exodus significantly, and the vacancy rate in places such as Daqing and Hegang is relatively high. The population loss is accompanied by a serious shortage of talents, insufficient endogenous motivation, and a lack of core competitiveness in cities. Due to the large population loss, the rest are basically the elderly, and social security issues such as old-age care have exacerbated the burden on cities. The serious loss of population has caused major damage to these resource-based cities.Climate conditions restrict economic development. (3) Heilongjiang has a high latitude and severely cold climate, which leads to high heating costs, limited market trading time, and is extremely unfavorable for outdoor construction and operations. For cities that focus on resource development. In other words, its impact is more serious. The cost of oil extraction in Daqing has increased and outdoor operations have been restricted; coal mining, processing and transportation, and the underforest economy in Jixi have all lost their vitality under the severe cold, which has restricted the development of Heilongjiang's resource-based cities.

Heilongjiang Province not only has a large number of resource-based cities, but also has its own shortcomings, Zeng, W.P. (2013). This determines that the transformation and 
development of resource-based cities in Heilongjiang Province is imperative, and the road to transformation is not smooth.

\section{References}

Austin, D.A (2006). New Method for Computing the Mean Center of Population of the United States. Professional Geographer, 58(1), p65-69.

Dai, X.F. (2009). How to transform resource-exhausted cities from international experience.China Today Forum, (1) p15-18.

$\mathrm{Hu}$, Z.C.(2018).The development status, law, trend and typical analysis of characteristic industries in resource-based cities. Farm Staff, (08), p213.

Hardi, P., Barg, S., Hodge, T. (eds.) (1997). Measuring Sustainable Development: Review of Current Practice. Ottawa: Industry Canada.

Karen Williamson (2003). Growing with infrastructure. Heritage Conservancy, 1(8), p1-6.

$\mathrm{Li}, \mathrm{F}$. (eds.) (2009) .Measurement indicators and an evaluation approach for assessing urban sustainable development: A case study for China's Jining City. Landscape and Urban Planning, 90(3-4), p0-142.

Liu, Y. and Liu, Y.(2003). Evaluation Index System and Trend Analysis of China's Regional Sustainable Development. China Soft Science, (7), p113-118.

Papurakis, E. and Gerlagh, R (2007). Resource abundance and economic growth in United States. European Economic Review, 51(4) p1011-1039.

State Council of China (2013). National Resource-based City Sustainable Development Plan (2013-2020) [online] Available at: http://www.gov.cn/zwgk/201312/03/content_2540070.htm. (Accessed:10 July 2021)

Thorson, J.T, Pinsky, M.L, Ward, E.J (2016). Model-based inference for estimating shifts in species distribution, area occupied, and center of gravity. Methods in Ecology\&Evolution, 7(8) p990-1002.

Xu, J.Z. and Liu, X.S. (eds.) (2002). Principal Component Analysis of Sustainable Development of Mining Resource City Economy. Journal of Harbin Engineering University, (5) p112-118.

Yang, D.G. and Niu, W.Y. (eds.) (2000). Evaluation of Comprehensive Advantages of Regional Sustainable Development in China. Scientific Management Research, 18(5) p70-78.

Yu, J.H, Li, J.M, Zhang, W.Z. (2018). Identification and comprehensive type classification of resource-based cities in China. Acta Geographica Sinica, 73(4): 677-687.

Zhao, K.J. (eds.) (2019) Green development and prosperity of resource-based cities. China: China Construction Industry Publishings.

Zhao, J.H. (2006). Review of research progress on resource-based city development in China. Urban Development Research, 13(3) p86-91.

Zeng, W.P. (2013) Research on the Transformation Policy of China's Resource-based Cities. Institute of Fiscal Science: Ministry of Finance

Zang, S.Y. (1999). Discussion on Sustainable Development Countermeasures of Resourcebased Cities_- Taking Jixi City as an Example. Resource Science, (1) p51-56.

Zhang, J.T. (2003). Research on Economic Globalization and Industrial Structure Transformation of my country's Resource-based Cities. Resource and industry, (3) p36-37.

Zhang, K.M. (1997) Sustainable development. China: China Environmental Science Publishings.

Zhang, W.Z. Yu, J.H. Wang, D. (eds.) (2014) Research on Sustainable Development of Resource-based Cities in China. Beijing: Science Publishings. 